ORIGINAL RESEARCH PAPER

\title{
DEVELOPMENT OF AN INNOVATIVE FROZEN DAIRY PRODUCT FORTIFIED WITH CARROT EXTRACT
}

\author{
MIHAELA TURTURICĂ ${ }^{*}$, ELENA ENACHI, VASILICA BARBU, GABRIELA ELENA BAHRIM
}

Dunărea de Jos University, 111 Domnească Street, 800201 Galati, Romania

*corresponding author: mihaela.turturica@ugal.ro

Received on 30 August 2021

Revised on 10 November 2021

\begin{abstract}
The development of frozen yogurt supplemented with an oily extract from carrot was the main focus of this study. The research aim converged from the fact that Daucus carota $\mathrm{L}$. are among the worldwide most consumed vegetables, exhibiting numerous health benefits. Both analysed variants (the control sample and the fortified sample) presented high total carotenoids, $\beta$-carotene, and lycopene contents. The addition of the oily extract from carrot caused a significant increase of the total carotenoids, respectively the $\beta$-carotene contents. Also, these functional dairy products registered a slight increase in the antioxidant activity compared to the control sample, the fortified variant having the highest value $(93.95 \pm 0.050 \%)$. The total polyphenols content varied depending on the analysed variant, from $0.122 \pm 0.006$ to $1.712 \pm 0.008 \mathrm{mg} / \mathrm{g}$ dry weight (DW) while the content of total flavonoids varied from $0.065 \pm 0.001$ to $0.780 \pm 0.002$ $\mathrm{mg} / \mathrm{g}$ DW. The carrot and blueberries' HPLC profiles also highlighted the abundance of the bioactive compounds. The confocal microscopy analysis of the fortified frozen yogurt revealed a complex microstructure due to the diversity of the biochemical compounds, a microstructure that preserved the probiotic strain very well and comprised functional properties to the final product. The frozen dairy product enriched with carrot extract can be considered an innovative functional product as it was designed to provide the consumer with various beneficial effects based on its high content of biologically active compounds.
\end{abstract}

Keywords: frozen yogurt, blueberry, carrot, anthocyanins, carotenoids, capsules, encapsulation

\section{Introduction}

In the past years, the world's tendency regarding the production of functional foods has been focused on promoting healthy and nutritive products based on bioactive compounds (Vulić et al., 2019). The expansion of the food industry leads to the

https://doi.org/10.35219/foodtechnology.2021.2.06 
creation of new products, economically viable, supported within the 'bioeconomy' concept (Gil-Chavez et al., 2013; Ravindran and Jaiswal, 2016).

Yogurt is the most popular dairy product around the world, a food product that plays several roles in human health because it delivers a high amount of bioactive compounds and improves microflora with probiotic strains and other lactic acid bacteria (LAB) (Fazilah et al., 2018). Yogurt is known to be the most consumed food product containing a large number of probiotic cells for therapeutic effects. The probiotic effects are influenced both by the ability of the organism to survive in the host and also in the product. For obtaining a beneficial effect, the amount of $\mathrm{LAB}$ in the product has been prescribed to be $10^{7} \mathrm{cfu} / \mathrm{ml}$ (Krasaekoopt et al., 2006).

There are numerous health benefits of probiotic bacteria described in research studies that can link them to the incorporation into a wide range of food products, such as yogurt, ice cream, etc. (Anal and Singh, 2007). The probiotics definition by Health Canada (2009) in their guidelines for foods is that they can be considered as being "live microorganisms which, when administered in adequate amounts, confer a health benefit on the host" (Sandoval-Castilla et al., 2010). According to the studies of Sandoval-Castilla et al. (2010), it would be better for probiotics to be entrapped within a limited range of bead sizes for satisfying incorporation into foods, for minimization of problems such as cell viability or food texture.

According to the research of Taksima et al. (2015), more than $70 \%$ of the functional food products in the market, are present in the form of a fermented dairy product. Mollakhalili Meybodi et al. (2020) reported in their study that if consuming yogurt, humans can develop a higher tolerance against food pathogens, it improves their immune system and the absorption of lactose and essential minerals. The main focus in the field of dairy products is on the addition of new ingredients, in order to create new yogurt variants with higher properties compared to traditional yogurt (Šeregelj et al., 2021).

Frozen yogurt (or yogurt ice cream) is a dairy type product, consumed as a healthful alternative to conventional ice cream, due to its bioactive compounds content and the presence of lactic acid bacteria. Frozen yogurt is as the name suggests, a frozen dessert, that can contain different food additives, etc. (FAO/WHO, 2003), and is present worldwide in any type of market at all times (Skryplonek et al., 2019).

According to the research studies of Terpou et al. (2019), the most used lactic acid bacteria (LAB), in the obtaining process of dairy products is Lactobacillus casei. Due to the in vitro and in vivo studies, we know that they can survive along the gastrointestinal tract, adhering to the intestine and also resisting during storage at lower temperatures (Terpou et al., 2019). Bosnea et al. (2017) used specifically in their studies, the strain L. casei ATCC 393 for the production of yogurt, Farias et al. (2019) for the production of ice cream, Abdel-Hamid et al. (2019), and Terpou et al. (2017a) for the fermented milk, and Terpou et al. (2017b) for the obtainment of cheese. 
In order to provide consumers with frozen products such as ice-cream, with many beneficial effects on human health, frozen desserts can be supplemented with extracts of fruits or vegetables, with lactic acid bacterias, or a combination of both (Terpou et al., 2019).

The objectives of the study were the valorification of carrot by encapsulating its bioactive compounds in alginate beads using the electrostatic extrusion technique, and also the development of a new type of frozen yogurt. Furthermore, to highlight their functionality, the bioactive contents, and the digestibility of the obtained product were evaluated during the frozen yogurt shelf-life.

\section{Materials and methods}

\section{Materials}

Fresh Daucus carota sp. and fresh Vaccinium myrtillus L., were purchased from the local market, Galati, Romania in June 2021. Formic acid, methanol, ethyl acetate, acetonitrile, sodium carbonate, aluminium chloride, sodium nitrite, sodium hydroxide, $\quad \mathrm{ABTS}^{+}(2,20$ azinobis (3-ethylbenzothiazoline-6-sulfonic acid) diammonium salt), and Folin-Ciocalteu's reagent were purchased from SigmaAldrich Chemical Co. (USA). The carotenoids standards ( $\beta$-carotene, lycopene, lutein), were purchased from Sigma-Aldrich Chemical Co. (China). The anthocyanins standards (delphinidin-3-galactoside, delphinidin-3-glucoside, cyanidin-3-galactoside, delphinidin-3-arabinoside, cyanidin-3-glucoside, petunidin3-galactoside, petunidin-3-glucoside, peonidin-3-galactoside, petunidin-3arabinoside, malvidin-3-galactoside, malvidin-3-glucoside, malvidin-3arabinoside) were acquired from Sigma-Aldrich Chemical (Germany) and Extrasynthese (France). Gallic acid and catechin standards were acquired from Sigma-Aldrich Chemical (Germany).

\section{Microbial culture}

A Lactobacillus casei strain (DSMZ, Braunschweig, Germany) was used for the frozen yogurt manufacture. L. casei was grown at $37^{\circ} \mathrm{C}$ in a MRS liquid medium (De Mann, Rogossa and Sharpe, Sigma Aldrich, GermanyMerck,) for 48 - $72 \mathrm{~h}$ under anaerobic conditions $\left(7 \% \mathrm{CO}_{2}\right.$ and $11.5 \% \mathrm{O}_{2}$, Sanyo, MCO-18M, Japan, Sakata). The obtained L. casei biomass was harvested by centrifugation (Hettich, Universal 320R, Germany) at $5000 \mathrm{rpm}$ for $10 \mathrm{~min}$ at $4^{\circ} \mathrm{C}$. A $10^{12} \mathrm{CFU} / \mathrm{mL}$ inoculum was prepared and added to the encapsulation step.

\section{Preparation of oily carrot extract and encapsulation in beads}

The procedure used for obtaining the carrot extract was performed according to Šeregelj et al. (2021). In short, the fresh carrot was mixed with sunflower oil at $25^{\circ} \mathrm{C}(1: 10 \mathrm{w} / \mathrm{v})$ by stirring with a ProBlend Crush blender for $20 \mathrm{~min}$ (Philips, Romania), applying repeated cycles of 5 min blend and 2 min pause, in order to avoid heating. Afterward, the oily extract was centrifuged at $6000 \mathrm{rpm}$ for $10 \mathrm{~min}$ (Hettich, Universal 320R, Germany), the supernatant was recovered and stored in a dark glass bottle for further use. 
The encapsulation step of the oily carrot extract was performed according to Šeregelj et al. (2021), using alginate as the carrier. A 2\% sodium alginate solution was prepared using ultrapure water under magnetic stirring at $700 \mathrm{rpm}$ (IKA RCT basic, Germany). The proportion of the carrot extract added to the alginate solution was $25 \%$. To the final emulsion, it was added the L. casei culture obtained previously, which stayed under magnetic stirring at $300 \mathrm{rpm}$ (IKA RCT basic, Germany) for another 5 minutes, in order to allow good incorporation. The obtained alginate/carrot extract/LAB emulsion was extruded through a $0.5-\mathrm{mm}$ blunt stainless-steel needle using a syringe pump (LKB Bromma 12000 Varioperpex peristaltic pump, Sweden) under a constant flow rate. The carrot extract beads were maintained in a calcium chloride solution for one hour in order to finalize their formation. At last, the obtained carrot extract beads were washed using ultrapure water and stored at ambient temperature before freeze-drying (Alpha CHRIST 1-4 LD Plus, Germany). Freeze-dried carrot extract beads were stored at $20^{\circ} \mathrm{C}$ until further analyses.

\section{Preparation of frozen yogurt samples}

In order to prepare the samples, a standard yogurt (as control and the basis for the fortified product) was acquired from the local market Galati, Romania. Briefly, 140 $\mathrm{g}$ of yogurt, $100 \mathrm{~g}$ mascarpone, $150 \mathrm{~g}$ of blueberries, $3 \mathrm{~mL}$ of vanilla extract, and $10 \mathrm{~g}$ of vanilla sugar were homogenized, and the packaging step of yogurt was continued. The yogurt was filled in plastic containers and kept overnight at $-20^{\circ} \mathrm{C}$ in a freezer, in order to obtain frozen yogurt (control sample - CFY).

In the case of fortified frozen yogurt (FFY), carrot extract beads containing LAB were added to the yogurt, before the packaging step. The fortified variant was also transferred into plastic containers and kept overnight at $-20^{\circ} \mathrm{C}$ in a freezer.

For all the analysis, the fortified sample (FFY) and the control sample (CFY), were prepared in triplicate.

\section{Characterization of fortified frozen yogurt}

\section{Digestibility}

For the analysis of the in vitro digestibility of the frozen yogurt samples, the method described by Barbu et al. (2020) was used. The gastric digestion simulation was made using a mixture that contained $20 \mathrm{mg}$ pepsin from porcine gastric

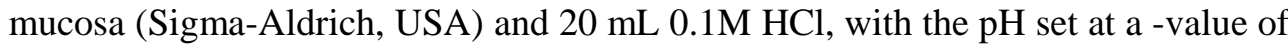
2.0. The aforementioned mixture that contained simulated gastric juice and also 10 $\mathrm{mL}$ of sample $(500 \mathrm{mg}$ of sample dissolved in $10 \mathrm{~mL} 20 \mathrm{mM}$ Tris buffer with a $\mathrm{pH}$ of 7.7) was incubated at $37^{\circ} \mathrm{C}$ on an orbital shaker (Incubated shaker SI-300R, Korea) at $150 \mathrm{rpm}$, aliquots being taken and analyzed every $30 \mathrm{~min}$. The mixture used for simulating the intestinal digestibility consisted of $40 \mathrm{mg}$ of pancreatin from porcine pancreas (Sigma-Aldrich, USA) and $20 \mathrm{~mL}$ of $0.9 \mathrm{M} \mathrm{NaHCO}$, with the $\mathrm{pH}$ set at a value of 7.0. The mixture that contains intestinal simulated juice and also $10 \mathrm{~mL}$ of sample (10 mL taken from the remaining simulated gastric juice) was incubated (Incubated shaker SI-300R, Korea) using the same conditions as in 
the case of the gastric simulation. The determination of carotenoids and anthocyanins contents was assessed as previously described.

\section{Confocal Laser Scanning Microscopy}

The images were obtained by using a Zeiss confocal laser scanning system (LSM 710) equipped with different lasers (a diode laser, Ar-laser, DPSS laser and HeNelaser) of the new functional nutraceutical product based on an oily carrot extract and LAB. In order to observe in detail, the $L$. casei cells and the vegetal microstructures present in this functional product, a Live/Dead stain kit (Molecular Probes, Eugene, OR, USA) was used, following the manufacturer's instructions.

A Zeiss Axio Observer Z1 inverted microscope equipped with a 40x apochromatic objective (numerical aperture 1.4) was used for the analysis of the samples. The 3D images were processed using the ZEN 2012 SP1 Black edition software. The evaluation was made on a minimum number of twenty fields, with each assay being performed in triplicate.

\section{Phytochemical analysis}

Carotenoids determination and the encapsulation efficiency

Total carotenoids (TC), $\beta$-carotene (BC), and lycopene (LC) contents in beads were determined after they were dissolved in $2 \%$ sodium citrate solution in a ratio of 1:7 w/v for $15 \mathrm{~min}$, with vigorous stirring on Vortex (BenchMixer, Taiwan) to allow chemical dissolution. After dissolving, the carotenoids were extracted with a mixture of hexane:acetone $(1: 3, \mathrm{v} / \mathrm{v})$, and their contents were determined spectrophotometrically at a wavelength corresponding to the maximum absorption of each of the carotenoids with a Biochrom Libra S22 (Holliston, MA) equipment:

Equation 1 was further used (Mihalcea et al., 2021):

$$
\text { Bioactive compounds content }(\mathrm{mg} / \mathrm{g} \mathrm{DW})=\frac{A \cdot M_{W} \cdot D f}{\varepsilon \cdot L}
$$

where $\mathrm{A}$ is the absorption at $450 \mathrm{~nm}$ for total carotenoids, at $470 \mathrm{~nm}$ for $\beta$-carotene, and at $503 \mathrm{~nm}$ for lycopene, $\mathrm{D}_{\mathrm{f}}$ is the sample dilution rate, $\mathrm{L}$ is the cell diameter of the spectrophotometer $(1 \mathrm{~cm})$.

To quantify the total carotenoids (TC), $\beta$-carotene (BC), and lycopene (LC), the molecular weights (MW) and molar extinction coefficients $(\varepsilon)$ of the representative compounds were undertaken i.e. total carotenoids $\left(\varepsilon=2590 \mathrm{~L} / \mathrm{mol} \mathrm{cm}^{-1}\right.$ in hexane:acetone, $\left.\mathrm{M}_{\mathrm{W}}=536.88 \mathrm{~g} / \mathrm{mol}\right), \beta$-carotene $\left(\varepsilon=2500 \mathrm{~L} / \mathrm{mol} \mathrm{cm}^{-1}\right.$ in hexane:acetone; $\left.\mathrm{M}_{\mathrm{W}}=536.88 \mathrm{~g} / \mathrm{mol}\right)$ and lycopene $\left(\varepsilon=3450 \mathrm{~L} / \mathrm{mol} \mathrm{cm}^{-1}\right.$ in hexane:acetone; $\mathrm{M}_{\mathrm{W}}=536.88 \mathrm{~g} / \mathrm{mol}$ ).

The encapsulation efficiency (EE\%) of the $\beta$-carotene, was calculated according to the equation below (Šeregelj et al., 2021), where $\beta$-CarI represents initial $\beta$ carotene added to the emulsion and $\beta$-CarB represents $\beta$-carotene content in the beads: 


$$
\mathrm{EE}(\%)=(\beta-\mathrm{CarB} / \beta-\mathrm{CarI}) \times 100
$$

\section{Total monomeric anthocyanin content}

In order to determine the total monomeric anthocyanin content (TMA) the AOAC (2005.02) official method was used and the TMA content was expressed as mg of cyanidin 3-glucosides equivalents (CGE) per g dry weight (DW), based on the method described by Oancea et al. (2018). The results were expressed as mg of cyanidin-3-glucoside equivalents $(\mathrm{C} 3 \mathrm{G})$ per gram dry weight $(\mathrm{DW})$.

\section{Total Phenolic Content}

The total phenolic content (TPC) was determined as stated by Barbu et al. (2020), by using the Folin-Ciocalteu reagent. By adding $200 \mu \mathrm{L}$ of extract over $15.80 \mathrm{~mL}$ of ultrapure water and $1000 \mu \mathrm{L}$ of Folin-Ciocalteu reagent was obtained a mixture that was maintained 10 minutes in the dark to react. After the reaction time, 3000 $\mu \mathrm{L}$ of $20 \% \mathrm{Na}_{2} \mathrm{CO}_{3}$ was added, and the final mixture was maintained in the dark at room temperature for 60 minutes in order to react. The absorbance was measured at a wavelength of $765 \mathrm{~nm}$. The results were expressed as $\mathrm{mg}$ of gallic acid equivalents (GAE) per gram dry weight (DW).

\section{Total flavonoids content}

The total flavonoids content (TFC) was determined using the colorimetric method described by Oancea et al. (2018), and the results were expressed as mg catechin equivalents (CE) per gram dry weight (DW). In order to determine total flavonoids, a mixture was prepared that contained $250 \mu \mathrm{L}$ of extract, $1.25 \mathrm{~mL}$ of ultrapure water, and $75 \mu \mathrm{L}$ of $5 \% \mathrm{NaNO}_{2}$, which was allowed to react for 5 minutes. Over this mixture $150 \mu \mathrm{L}$ of $10 \%$ aluminum chloride solution which was also let to react for 6 minutes. Finally, $500 \mu \mathrm{L}$ of $1 \mathrm{M} \mathrm{NaOH}$ solution and ultrapure water until $3 \mathrm{~mL}$ final volume were added. The absorbance was measured immediately at a wavelength of $510 \mathrm{~nm}$.

\section{Antioxidant Activity}

The antioxidant capacity (AA) was employed as described by Gheonea et al. (2021), by using the 2,20 azino-bis (3-ethylbenzothiazoline-6-sulfonic acid) diammonium salt ( $\mathrm{ABTS}^{+}$, Sigma Aldrich, Steinheim, Germany) radical's method. The ABTS.+ antioxidant activity of the samples was expressed as $\mathrm{mM}$ Trolox equivalents/g DW based on the calibration curve. The percent inhibition of ABTS ${ }^{+}$ was calculated as follows:

Antioxidant activity $(\%)=\frac{\text { Abs. of the blank-Abs. of the sample }}{\text { Abs. of blank }} \cdot 100$

\section{Identification of biologically active compounds}

Carotenoids found in the fresh carrot sample were identified using the chromatographic analysis, as described by Ursache et al. (2017). 
Briefly, the carrot extract was prepared by mixing $0.1 \mathrm{~g}$ of fresh sample with $10 \mathrm{~mL}$ of hexane, and then ultrasonication for 30 minutes (MRC Scientific Instruments), followed by a centrifugation step at $6000 \times \mathrm{g}$, at $4{ }^{\circ} \mathrm{C}$ for $5 \mathrm{~min}$. The obtained supernatant was filtered through $0.2 \mu \mathrm{m}$ nylon membranes and then injected into the Surveyor HPLC system (Finnigan Surveyor LC, Thermo Scientific, Waltham, USA) equipped with a Lichrosorb RP-18 $(5 \mu \mathrm{m})$ Hibar RT 125-4 column (Phenomenex, Torrance, USA). Compounds of interest were detected at a wavelength of $450 \mathrm{~nm}$.

Anthocyanins found in the fresh blueberry sample were identified using chromatographic analysis, based on the method described by Condurache et al. (2021).

The blueberry extract was prepared from $1.0 \mathrm{~g}$ of fresh blueberry and $10 \mathrm{~mL}$ of $80 \%$ methanol followed by ultrasonication for 30 minutes (MRC Scientific Instruments). The sample was centrifuged and filtered before injection, by using $0.22 \mu \mathrm{m}$ syringe filters (Bio Basic Canada Inc., ON, Canada). A Hypersil BDS C18 column $(150 \times 4.6 \mathrm{~mm}, 5 \mu \mathrm{m})$ was used, maintained at a temperature of $30^{\circ} \mathrm{C}$. The mobile phase consisted of $100 \%$ pure methanol (A) and 10\% formic acid (B), whereas the injection volume was $20 \mu \mathrm{L}$, at a $1 \mathrm{~mL} / \mathrm{min}$ flow rate. The detection was specifically set at a wavelength of $520 \mathrm{~nm}$.

\section{Statistical Analysis of Data}

All the data reported in this research study represents the averages of a triplicate analysis and was reported as mean \pm standard deviation. The analysis of variance (ANOVA) $(\mathrm{p}<0.05)$ was carried out to assess the significant differences between the obtained values.

\section{Results and discussion}

\section{Confocal Laser Scanning Microscopy}

The confocal analysis of the frozen fortified yogurt revealed a complex microstructure due to the diversity of the biochemical compounds that are part of the product. With a fairly high frequency (approximately 70\%), it could be seen several well-preserved fragments of the plant tissue in the root parenchyma of Daucus carota. As it can be seen in Figure 1, the cells present almost intact cell walls (shown in yellow) being full of chromoplasts (in green) that contain carotenoids with a fluorescence emission in the range of 500-550 nm. Around these tissue fragments, with the help of the Live/Dead stain kit, dense masses of lactic acid bacteria (L. casei microcolonies) were highlighted, in a proportion of $80-90 \%$ alive (colored in green) and 10-20\% dead (colored in red). The chosen method of microencapsulation of the biologically active compounds from carrot root, as well as the preparation of the frozen fortified yogurt, are original methods that preserved the probiotic strains very well and gave functional properties to the product. 


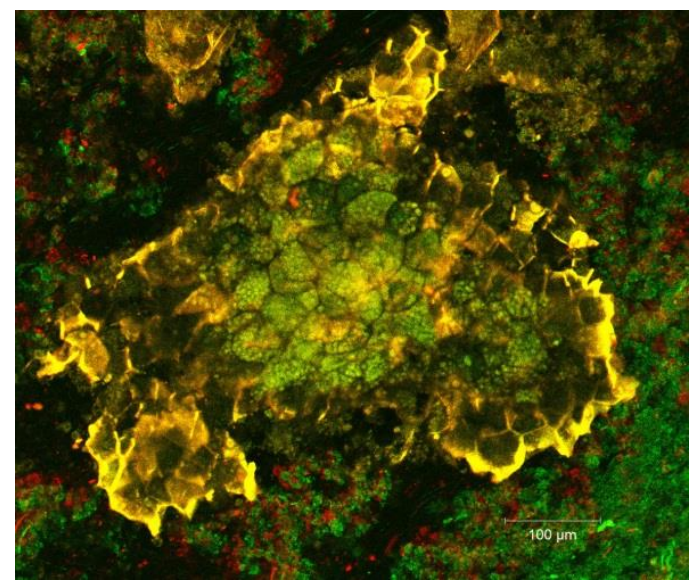

Figure 1. CLSM images of fortified frozen yogurt microstructure.

\section{Carotenoids Quantification, Total Polyphenols Content, Total Flavonoids Content, and Antioxidant Activity}

The contents of the bioactive compounds and the antioxidant activity differed significantly $(\mathrm{p}<0.05)$ when comparing the values obtained for the CFY sample and the FFY variant. As such, the total carotenoids content, $\beta$-carotene content and lycopene content in the CFY sample (control sample) presented the following values $0.005 \pm 0.001 \mathrm{mg} / \mathrm{g} \mathrm{DW}, 0.016 \pm 0.004 \mathrm{mg} / \mathrm{g} \mathrm{DW}$, and $0.006 \pm 0.0 \mathrm{mg} / \mathrm{g}$ DW, respectively (Table 1$)$. The FFY variant displayed significantly $(\mathrm{p}<0.05)$ higher TC, BC, and LC contents compared to the control sample 89.885 \pm 4.429 $\mathrm{mg} / \mathrm{g}$ DW, $78.901 \pm 3.417 \mathrm{mg} / \mathrm{g} \mathrm{DW}$, and $24.911 \pm 1.698 \mathrm{~g} / \mathrm{g}$ DW respectively (Table $1)$.

The microencapsulation method was used in this research study to obtain highquality beads, by minimizing oxidative degradation of carotenoids during the freeze-drying process. The encapsulation efficiency (EE) of $\beta$-carotene was obtained by dividing the amount of $\beta$-carotene in the product with that from the extract. The encapsulation efficiency was $23.36 \pm 0.13 \%$, implying a loss of bioactive compounds during freeze-drying, which may be caused by the mass loss. Gheonea et al. (2021) reported an encapsulation efficiency of lycopene of $83.6 \pm 0.020 \%$, Jia et al. (2020) reported an encapsulation efficiency and an encapsulation yield of $94 \%$ and $86 \%$ for lycopene microencapsulation in whey protein isolate conjugated with xylo-oligosaccharides via Maillard reaction. Sampaio et al. (2019) reported a maximum lycopene encapsulation efficiency of $100 \%$. The EE of $\beta$-carotene reported by Mihalcea et al. (2018), was $36.23 \pm 1.58 \%$. Mihalcea et al. (2017) reported a significantly higher EE of $\beta$-carotene from the sea buckthorn (SBT) extract obtained using supercritical $\mathrm{CO}_{2} \quad 46.18 \pm 0.13 \%$. Rodríguez-Huezo et al. (2004) reported an EE varying from $25.6 \%$ to $87.5 \%$. Ursache et al. (2018) reported a higher value of $56.16 \pm 1.24 \%$ for microencapsulation of carotenoids extracted from SBT using conventional methods. 
The content of total monomeric anthocyanin content (TMA) in the CFY sample was $0.013 \pm 0.001 \mathrm{mg}$ cyanidin-3-glucoside $(\mathrm{C} 3 \mathrm{G}) / \mathrm{g}$ DW (Table 1) whereas the FFY sample had a content of TMA of $0.774 \pm 0.015 \mathrm{mg} \mathrm{C} 3 \mathrm{G} / \mathrm{g}$ DW. It can be stated that the addition of the selected fruits (blueberries) caused a significant increase in the content of the bioactive compounds.

Because of the low temperature, air presence, and light, the oxidation reactions are limited, therefore the bioactive content in the product is substantially preserved (Cui et al. 2008). In the case of carrots, the antioxidant activity is usually correlated with the $\beta$-carotene content, whereas in the case of blueberries it is correlated with the total anthocyanins and polyphenolic contents. Moreover, it is known that processed fruits and vegetables have lower antioxidant activity compared to raw or fresh due to vitamin $\mathrm{C}$ degradation during processing (Lau et al., 2018).

The FFY sample registered an inhibition of $93.95 \pm 0.050 \%$, compared to the CFY sample that exhibited a $30.71 \pm 0.014 \%$ inhibition (Table 1). These results can be correlated with the higher contents of both anthocyanins and carotenoids, but also with other compounds, besides the analyzed ones, that contribute to the antioxidant activity of the samples. Purkiewicz et al. (2020) concluded that the antioxidant activity of the orange and yellow carrot juices did not differ, whether using DPPH $(28.54 \pm 0.35 \mu \mathrm{mol}$ Trolox $/ \mathrm{mL}$ for orange carrot juices and $29.12 \pm 0.59 \mu \mathrm{mol}$ Trolox $/ \mathrm{mL}$ for yellow carrot juices) or ABTS assays $(3.28 \pm 0.01 \mu \mathrm{mol}$ Trolox $/ \mathrm{mL}$ for orange carrot juices and $3.15 \pm 0.01 \mu \mathrm{mol}$ Trolox $/ \mathrm{mL}$ for yellow carrot juices). Bystrická et al. (2015) managed to determine an antioxidant activity varying from $6.88 \pm 0.92 \%$ for the Jitka carrot variety, to $9.83 \pm 0.62 \%$ for the Koloseum carrot variety. Their results are similar to those obtained by Algarra et al. (2014) who determined an antioxidant activity between $1.4-17.6 \%$, and Bembem et al. (2014) who determined an antioxidant activity in carrots of $11.2 \%$.

Table 1. Phytochemical features of the CFY and the FFY samples.

\begin{tabular}{lll}
\hline & FFY & CFY \\
\hline TMA (mg/g DW) & $0.774 \pm 0.015^{\mathrm{a}}$ & $0.013 \pm 0.001^{\mathrm{b}}$ \\
TC $(\mathbf{m g} / \mathbf{g}$ DW) & $89.885 \pm 4.429^{\mathrm{a}}$ & $0.005 \pm 0.001^{\mathrm{b}}$ \\
$\mathbf{B C}(\mathbf{m g} / \mathbf{g}$ DW) & $78.901 \pm 3.417^{\mathrm{a}}$ & $0.016 \pm 0.004^{\mathrm{b}}$ \\
$\mathbf{L C}(\mathbf{m g} / \mathbf{g}$ DW) & $24.911 \pm 1.698^{\mathrm{a}}$ & $0.006 \pm 0.00^{\mathrm{b}}$ \\
TPC (mg GA/g DW) & $1.712 \pm 0.008^{\mathrm{a}}$ & $0.122 \pm 0.006^{\mathrm{b}}$ \\
TFC (mg CE/g DW) & $0.780 \pm 0.002^{\mathrm{a}}$ & $0.065 \pm 0.001^{\mathrm{b}}$ \\
AA (\%) & $93.95 \pm 0.050^{\mathrm{a}}$ & $30.71 \pm 0.014^{\mathrm{b}}$ \\
\hline
\end{tabular}

For each tested biologically active compounds content, the values from the same row that do not share a letter are statistically different at $p<0.05$ based on the Tukey method and 95\% confidence; TMA - total monomeric anthocyanin content; TC - total carotenoids content; $\mathrm{BC}-\beta$-carotene content; LC - lycopene content, TPC - total polyphenols content, TFC-total flavonoids content, AAantioxidant activity. 
The TPC content varied from $0.122 \pm 0.006 \mathrm{mg}$ gallic acid equivalents (GAE)/g DW in the case of the CFY sample to $1.712 \pm 0.008 \mathrm{mg} \mathrm{GAE} / \mathrm{g}$ DW for the FFY sample (Table 1). According to the studies of Purkiewicz et al. (2020), the total polyphenolic content varied between the carrot varieties, the higher content being registered for the black carrot juices, while the lower content was registered for the orange carrot juices. Another study conducted by Bystrická et al. (2015) on different varieties of carrots (Jitka, Kardila, Katlen, Rubína, and Koloseum) ranged from $81.25 \pm 13.11 \mathrm{mg} / \mathrm{kg}$ to $113.69 \pm 11.57 \mathrm{mg} / \mathrm{kg}$. Also, Bouzari et al. (2015) obtained a polyphenolic content in fresh carrots of $108 \mathrm{mg} \mathrm{GAE} / 100 \mathrm{~g} \mathrm{DW}$.

The TFC content varied from $0.065 \pm 0.001 \mathrm{mg}$ catechin equivalents (CE) in the case of CFY to $0.780 \pm 0.002 \mathrm{mg} \mathrm{CE} / \mathrm{g} \mathrm{DW}$ for the FFY variant (Table 1).

\section{Chromatographic analysis of the biologically active compounds}

In order to characterize the carotenoids from the fresh carrot extract, a chromatographic analysis was performed (Figure 2). The carotenoid identification was made depending on the retention time and by comparison with the available standards and the data existing already in the literature.

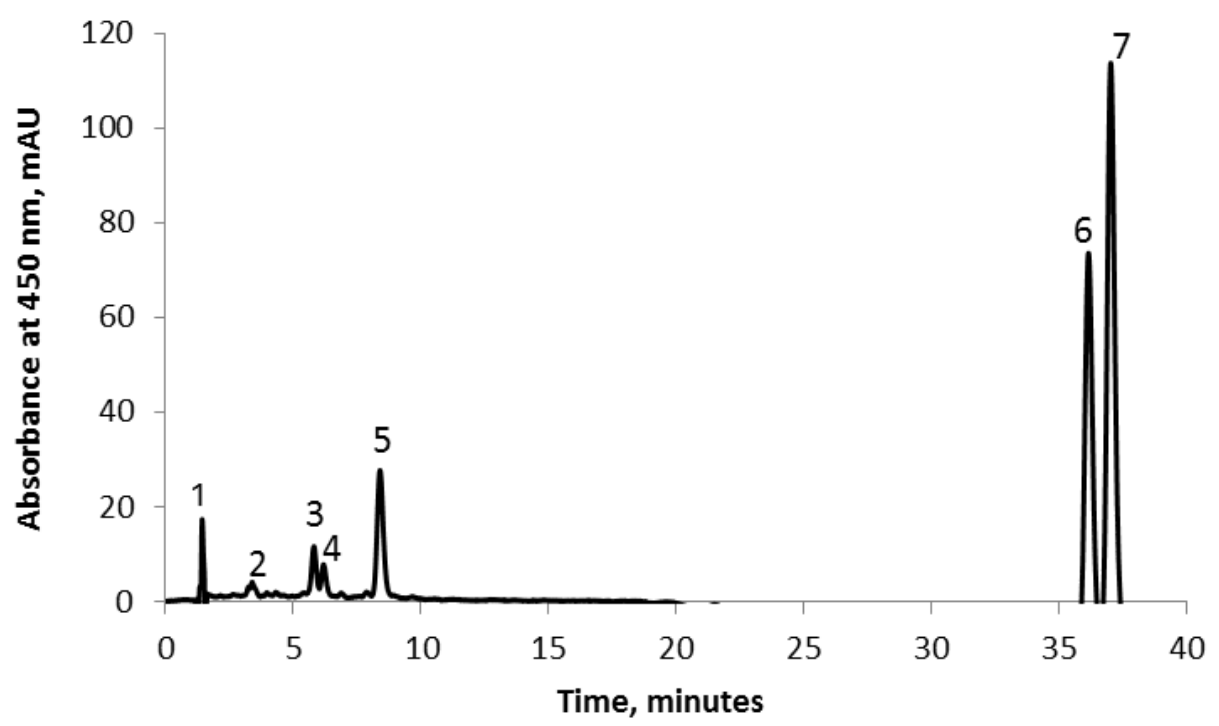

Figure 2. Chromatographic profile of fresh carrot extract. Peak $1-4$ - unidentified, peak 5 - lutein, peak 6 -lycopene, peak 7 - $\beta$-carotene.

The carotenoid identification was made at $450 \mathrm{~nm}$, and the chromatographic analysis revealed the presence of seven compounds in the carrot extract: $1-4-$ unidentified, 5 - lutein, 6 - lycopene, $7-\beta$-carotene. These results are in agreement with those obtained by Lau et al. (2018) on carrot peel extract. The highest peak was registered for the compound $\beta$-carotene, 29.69 $\pm 0.18 \mu \mathrm{g} \beta$ carotene/mL extract (Table 2). 
In their research study, Purkiewicz et al. (2020) managed to separate and identify five different carotenoids in yellow, orange, and black juices: $\alpha$-carotene, $\beta$ carotene, 13-cis- $\beta$-carotene, lutein, and zeaxanthin. In the orange carrot juices they highlighted that the dominant carotenoid was $\beta$-carotene, and the second dominant compound was 13-cis- $\beta$-carotene. Significant lower amounts of these two compounds were found in the black carrot juices (Purkiewicz et al. 2020).

Table 2. The detected carotenoids in the extract of fresh carrot by HPLC-DAD.

\begin{tabular}{cccc}
\hline Peak & Compound & $\mathbf{t}_{\mathbf{R}}$ & Carotenoid, $\boldsymbol{\mu g} / \mathbf{m L}$ \\
\hline 1. & Unidentified & $1.44 \pm 0.01$ & $\mathrm{NQ}$ \\
2. & Unidentified & $3.40 \pm 0.01$ & $\mathrm{NQ}$ \\
3. & Unidentified & $5.82 \pm 0.02$ & $\mathrm{NQ}$ \\
4. & Unidentified & $6.19 \pm 0.02$ & $\mathrm{NQ}$ \\
5. & Lutein & $8.14 \pm 0.01$ & $5.04 \pm 0.02$ \\
6. & Lycopene & $36.16 \pm 0.03$ & $17.98 \pm 0.10$ \\
7. & $\beta$-carotene & $37.02 \pm 0.02$ & $29.69 \pm 0.18$ \\
\hline
\end{tabular}

In another study conducted by Szczepańska et al. (2022) on carrot juice, seven carotenoids were separated and identified: phytoene, lutein, $\varepsilon$-carotene, $\alpha$-carotene, $\beta$-carotene, 9-Z- $\beta$-carotene, and $\delta$-carotene. In an early study, Szczepańska et al. (2021) managed to separate from the fresh carrot juice the following carotenoids, namely: lutein, $\beta$-cryptoxanthin, $\varepsilon$-carotene, 9-Z- $\beta$-carotene, $\alpha$-carotene and $\beta$ carotene, and one unidentified carotenoid.

In order to characterize the anthocyanins from blueberry extract, chromatographic separation was realized (Figure 3). The anthocyanins identification also was made depending on the retention time and by comparison with the available standards and the data existing already in the literature.

The identification of these compounds was made at $520 \mathrm{~nm}$, and the chromatogram revealed the presence of thirteen compounds in the blueberry extract: 1 delphinidin-3-galactoside, 2 - delphinidin-3-glucoside, 3 - cyanidin-3-galactoside, 4 - delphinidin-3-arabinoside, 5 - cyanidin-3-glucoside, 6 - petunidin-3galactoside, 7 - petunidin-3-glucoside, 8 - peonidin-3-galactoside, 9 - petunidin-3arabinoside, 10 - malvidin-3-galactoside, 11 - malvidin-3-glucoside, 12 unidentified, 13 - malvidin-3-arabinoside, with the highest peak being represented by malvidin-3-galactoside, $1854.84 \pm 2.10 \mu \mathrm{g} \mathrm{M} 3 \mathrm{G} / \mathrm{mL}$ extract (Table 3).

These results are in agreement with those obtained by Skrede et al. (2000) on highbush blueberries who reported 12 anthocyanins separated from the Bluecrop variety. 


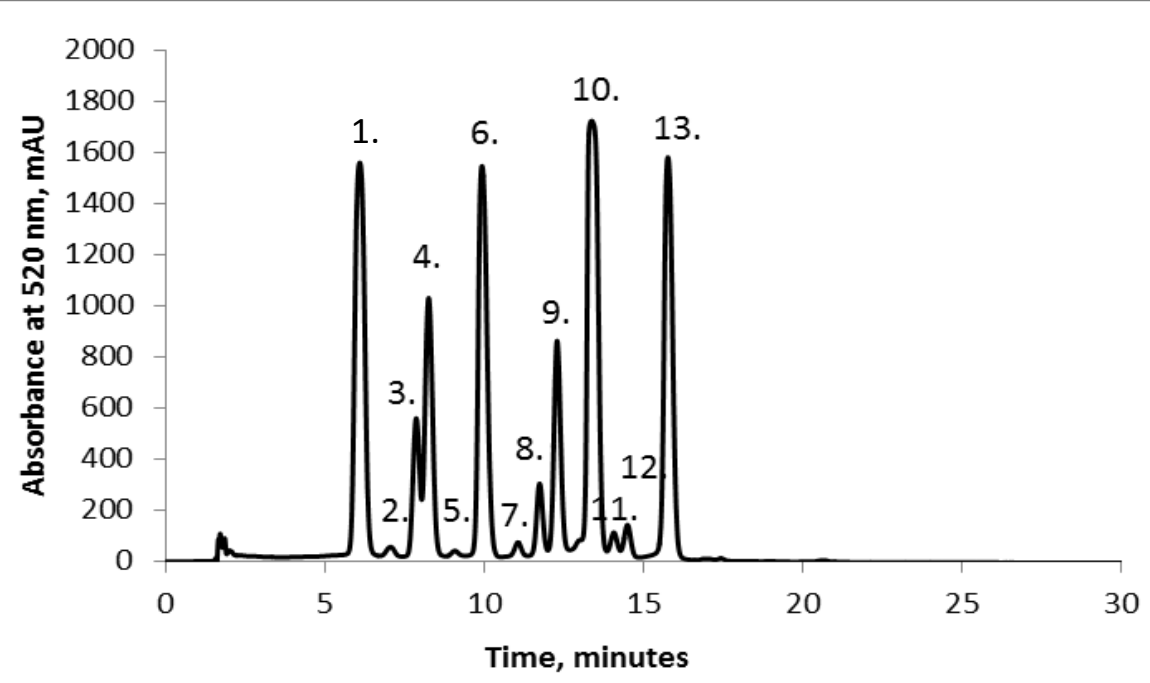

Figure 3. Chromatographic profile of fresh blueberry extract.

(peak 1 - delphinidin-3-galactoside, peak 2 - delphinidin-3-glucoside, peak 3 - cyanidin-3galactoside, peak 4 - delphinidin-3-arabinoside, peak 5 - cyanidin-3-glucoside, peak 6 petunidin-3-galactoside, peak 7 - petunidin-3-glucoside, peak 8 - peonidin-3-galactoside, peak 9 - petunidin-3-arabinoside, peak 10 - malvidin-3-galactoside, peak 11 - malvidin-3glucoside, peak 12 - unidentified, peak 13 - malvidin-3-arabinoside).

Table 3. The detected anthocynins in the extract of fresh blueberry by HPLC-DAD.

\begin{tabular}{cccc}
\hline Peak & Compound & tR & Anthocyanins, $\mathbf{\mu g} / \mathbf{m L}$ \\
\hline $\mathbf{1 .}$ & delphinidin-3-galactoside & 6.08 & $1533.013 \pm 1.91$ \\
2. & delphinidin-3-glucoside & 7.05 & $58.13 \pm 0.11$ \\
3. & cyanidin-3-galactoside & 7.86 & $362.99 \pm 1.54$ \\
$\mathbf{4 .}$ & delphinidin-3-arabinoside & 8.25 & $\mathrm{NQ}$ \\
$\mathbf{5 .}$ & cyanidin-3-glucoside & 9.07 & 38.39 \\
$\mathbf{6 .}$ & petunidin-3-galactoside & 9.92 & $\mathrm{NQ}$ \\
$\mathbf{7 .}$ & petunidin-3-glucoside & 11.06 & $68.64 \pm 0.15$ \\
$\mathbf{8 .}$ & peonidin-3-galactoside & 11.73 & $\mathrm{NQ}$ \\
$\mathbf{9 .}$ & petunidin-3-arabinoside & 12.28 & $\mathrm{NQ}$ \\
$\mathbf{1 0 .}$ & malvidin-3-galactoside & 13.37 & $1854.84 \pm 2.10$ \\
$\mathbf{1 1 .}$ & malvidin-3-glucoside & 14.07 & $83.27 \pm 0.21$ \\
$\mathbf{1 2 .}$ & Unidentified & 14.49 & $\mathrm{NQ}$ \\
$\mathbf{1 3 .}$ & malvidin-3-arabinoside & 15.76 & $1339.515 \pm 2.52$ \\
\hline
\end{tabular}

"NQ - not quantified

In another study conducted by Sun et al. (2012) on 11 batches of blueberry extracts, fourteen anthocyanins were also separated and identified, the highest peak being represented by delphinidin-3-galactoside, peonidin 3-glucoside, and malvidin 
3-glucoside. Also, 9 compounds were identified by Cesa et al. (2017) in a hydroalcoholic extract of blueberry samples, namely: delphinidin-3-O-galactoside; cyanidin-3-O-galactoside; delphinidin-3-O-arabinoside; petunidin-3-O-galactoside; cyanidin-3-O-arabinoside; petunidin-3-O-arabinoside; malvidin-3-O-galactoside; malvidin-3-O-glucoside and, malvidin-3-O-arabinoside. Also, our results are according to those obtained by Aliaño-González et al. (2020) who managed to separate 14 anthocyanins in the blueberry extract (delphinidin 3-O-galactoside, delphinidin 3-O-glucoside, cyanidin 3-O-galactoside, delphinidin 3-O-arabinoside, cyanidin 3-O-glucoside, petunidin 3-O-galactoside, cyanidin 3-O-arabinoside, petunidin 3-O-glucoside, peonidin 3-O-galactoside, petunidin 3-O-arabinoside, peonidin 3-O-glucoside, malvidin 3-O-galactoside, malvidin 3-O-glucoside, malvidin 3-O-arabinoside).

The quantification of the rest of the bioactive compounds identified by the HPLC chromatograms will be further examined in future studies.

\section{Digestibility of the Frozen Yogurt Products}

The in vitro digestibility analysis of the frozen yogurt products tried to evaluate the carotenoids and anthocyanins' behavior in both gastric and intestinal juices.

The biological activity of anthocyanins and carotenoid compounds, and their behavior in the gastrointestinal tract (Figure $4 \mathrm{a}, \mathrm{b}$ and Figure $5 \mathrm{a}, \mathrm{b}$ ), in regards to their beneficial properties on human health represents a complex process so that depending on their concentration may affect their release and absorption at the gastrointestinal level.

Pinto et al. (2017), stated that gastrointestinal digestion contributes to the release of total polyphenols from the food matrix. However, several transformations of polyphenolic compounds under gastrointestinal conditions can lead to a reduction in their potential bioactivity. Polyphenols are considered to be among the most unstable compounds in food, thus decreasing during the digestion step.

As the recipe indicates, the CFY sample did not contain any bioactive compounds from carrot. After 90 minutes of maintaining the FFY sample in contact with the simulated gastric juice, a release of the microcapsules was observed, in a percentage of $54.70 \pm 1.06 \%$, a value that increased by $9.38 \pm 1.44 \%$ after 120 minutes. In the case of the simulated intestinal juice, a decrease of $33.91 \pm 1.63 \%$ in the release of the carotenoids could be observed for the same sample, being afterward followed by an increase of $23.12 \pm 0.87 \%$. Furthermore, after 60 minutes a rather constant release of $\beta$-carotene was also assessed.

In terms of TMA, the CFY sample did not contain any bioactive compounds from blueberries. For the FFY variant, a constant decrease in the anthocyanins release was observed. In the intestinal digestion step, there was an increase in the release of anthocyanins of $12.26 \pm 0.07 \%$ after $30 \mathrm{~min}$, followed by a decrease of about $44.54 \pm 1.18 \%$ after $60 \mathrm{~min}$ for the FFY variant and an increase of $37.88 \pm 3.71 \%$ after $120 \mathrm{~min}$, while for the CFY sample also a constant level of the C3G content was observed. According to Zygmantaité et al. (2021), there was a gradual increase in the polyphenols that were released into the gastrointestinal fluids the during 
digestion of the yogurt samples. However, most polyphenols remained insoluble and were not released at all digestion times (Zygmantaité et al., 2021).

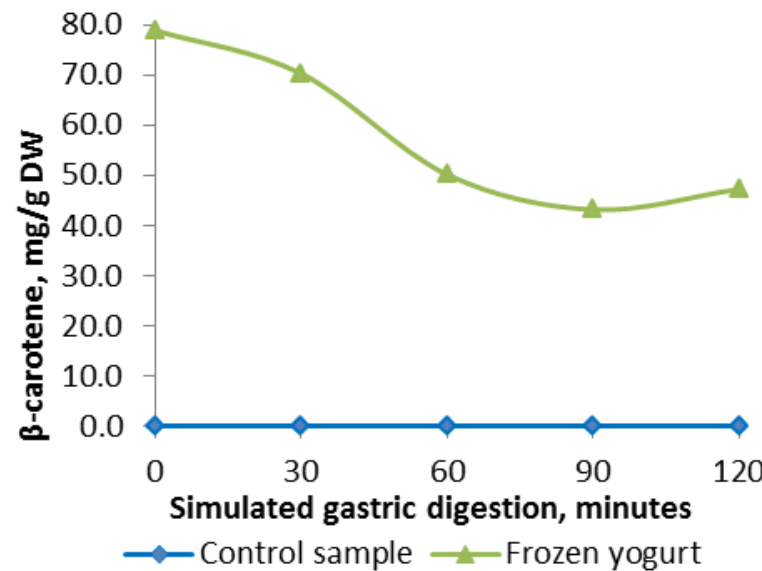

a)

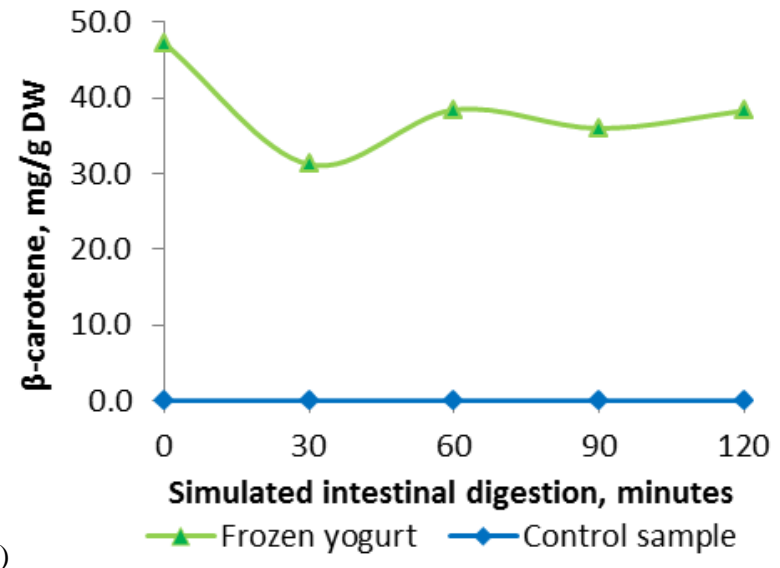

Figure 4. Effect of the simulated gastric (a) and intestinal digestion (b) on the level of $\beta$ carotene $(\mathrm{BC})$ released from the frozen yogurt.

The findings of Zygmantaite et al. (2021) highlighted the relationship between the formation of complexes between milk proteins and the phenolic-rich cranberry extract (Ozdal et al., 2013). The changes in digestibility were positively correlated to the strength of protein-polyphenol interactions (Stojadinovic et al. 2013). Other researchers have highlighted similar results. Pan et al. (2019) stated that $1 \%-5 \%$ pomegranate juice rich in polyphenols decreased the in vitro digestibility in yogurt. 


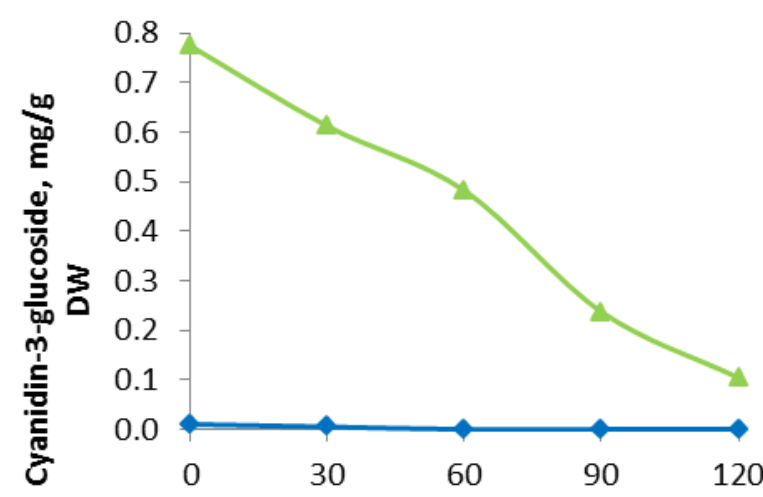

Simulated gastric digestion, minutes

a) $\longrightarrow$ Frozen yogurt $\multimap$ Control sample

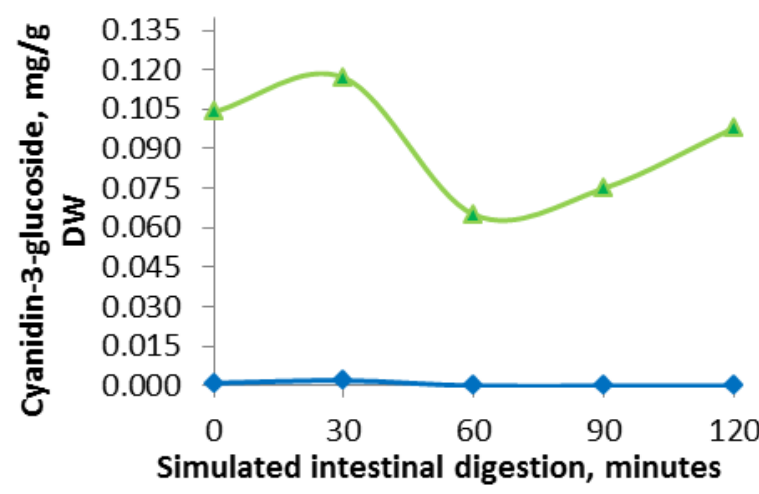

b)

$\leadsto$ Frozen yogurt $\multimap$ Control sample

Figure 5. Effect of the simulated gastric (a) and intestinal digestion (b) on the level of total monomeric anthocyanin content (TMA) released from the frozen yogurt.

\section{Conclusions}

This research study aimed to use oily extract produced from carrots and fresh blueberry fruits for the fortification of frozen yogurt. The fortified yogurt as an innovative product displayed high concentrations of carotenoids, $\beta$-carotene, lycopene, total polyphenols, total monomeric anthocyanins, and high antioxidant activity, so the final product can be considered and regarded as a functionally enhanced food product. These kinds of dairy products are ready for consumption, and they also can provide a sufficient daily intake of probiotics, being a dairy product. The health benefits exhibited by such products should be further examined.

\section{Acknowledgments}

The work of Mihaela Turturică was supported by the project ANTREPRENORDOC, in the framework of Human Resources Development 
Operational Programme 2014-2020, financed from the European Social Fund under the contract number 36355/23.05.2019 HRD OP /380/6/13 - SMIS Code: 123847.

The authors would like to thank for the technical support offered by the Integrated Center for Research, Expertise and Technological Transfer in Food Industry (BioAliment-TehnIA) and the MoRAS center, Grant POSCCE ID 1815, SMIS 48745 (www.moras.ugal.ro).

\section{References}

Abdel-Hamid, M., Romeih, E., Gamba, R.R., Nagai, E., Suzuki, T., Koyanagi, T., Enomoto, T. 2019. The biological activity of fermented milk produced by Lactobacillus casei ATCC 393 during cold storage. International Dairy Journal, 91, 1-8.

Algarra, M., Fernandes, A., Mateus, N., Freitas, V., Joaquim, C.G., Silva, E., Casad ,C.H. 2014. Anthocyanin profile and antioxidant capacity of black carrots (Daucus carota L. ssp. sativus var. atrorubens Alef.) from Cuevas Bajas, Spain. Journal of Food Composition and Analysis, 33, 71-76.

Anal, A., Singh, H. 2007. Recent advances in microencapsulation of probiotics for industrial applications and targeted delivery. Trends in Food Science and Technology, 18, 240-251.

Barbu, V., Cotarlet, M, Bolea, C.A., Cantaragiu, A., Andronoiu, D.G., Bahrim G.E., Enachi, E. 2020. Three Types of Beetroot Products Enriched with Lactic Acid Bacteria. Foods, 9, 786.

Bembem, K., Sadana, B. 2014. Effect of different cooking methods on the antioxidant components of Carrot. Bioscience Discovery, 5, 112-116.

Bosnea, L.A., Kopsahelis, N., Kokkali, V., Terpou, A., Kanellaki, M. 2017. Production of a novel probiotic yogurt by incorporation of L.casei enriched with fresh apple pieces, dried raisins, and wheat grains. Food and Bioproducts Processing, 102, 62-71.

Bouzari, A., Holstege, D., Barrett, D.M. 2015. Mineral, fiber, and total phenolic retention in eight fruits and vegetables: A comparison of refrigerated and frozen storage. Journal of Agricultural and Food Chemistry, 63, 951-956.

Bystrická, J., Kavalcová, P., Musilová, J., Vollmannová, A., Tóth, T., Lenková, M. 2015. Carrot (Daucus carota L. ssp. sativus (Hoffm.) Arcang.) as source of antioxidants. Acta agriculturae Slovenica, $\mathbf{1 0 5}(2), 303-311$.

Cesa, S., Carradori, S., Bellagamba, G., Locatelli, M., Casadei, M.A., Masci, A., Paolicelli, P. 2017. Evaluation of processing effects on anthocyanin content and colour modifications of blueberry (Vaccinium spp.) extracts: Comparison between HPLC-DAD and CIELAB analyses. Food Chemistry, 232, 114-123.

Condurache (Lazar), N.N., Turturica, M., Enachi, E., Barbu. V., Bahrim, G.E., Stanciuc, N., Croitoru, C., Rapeanu, G. 2021. Impact of Wall Materials on Physico-Chemical Properties and Stability of Eggplant Peels Anthocyanin Hydrogels. Inventions, 6, 47.

Cui, L., Niu, L.Y., Li, D.J., Liu, C.G., Liu, Y.P., Liu, C.J., Song, J.F. 2018. Effects of different drying methods on quality, bacterial viability and storage stability of probiotic enriched apple snacks. Journal of Integrative Agriculture, 17(1), 247-255.

FAO/WHO (Food and Agriculture Organization of the United Nations/World Health Organization). 2003. Codex Standard for Fermented Milks. Codex Stan 243-2003. 2nd ed. FAO/WHO, Rome, Italy.

Farias, T.G.S.D., Ladislau, H.F.L., Stamford, T.C.M., Medeiros, J.A.C., Soares, B.L.M., Arnaud, T.M.S., Stamford. T.L.M. 2019. Viabilities of Lactobacillus rhamnosus ASCC 290 and Lactobacillus casei ATCC 334 (in free form or encapsulated with calcium alginate-chitosan) in yellow mombin ice cream. $L W T$, 100, 391-396. 
Fazilah, N.F., Ariff, A.B., Khayat, M.E., Rios-Solis, L., Halim, M. 2018. Influence of probiotics, prebiotics, synbiotics and bioactive phytochemicalson the formulation of functional yogurt. Journal of Functional Foods, 48, 387-399.

Gheonea (Dima), I., Aprodu, I., Cîrciumaru, A., Râpeanu, G., Bahrim, G.E., Stănciuc, N. 2021. Microencapsulation of lycopene from tomatoes peels by complex coacervation and freeze-drying: Evidences on phytochemical profile, stability and food applications. Journal of Food Engineering, 288, 110166.

Gil-Chavez, G.J., Villa, J.A., Ayala-Zavala, J.F., Heredia, J.B., Sepulveda, D., Yahia, E.M., González-Aguilar, G.A. 2013. Technologies for extraction and production of bioactive compounds to be used as nutraceuticals and food ingredients: An overview. Comprehensive Reviews in Food Science and Food Safety, 12, 5-23.

Health Canada (2009). Guidance document. The use of probiotic microorganisms in food. Food directorate - Health products and food branch. 8pp.

Jia, C., Cao, D., Ji, S., Lin, W., Zhang, X., Muhoza, B. 2020. Whey protein isolate conjugated with xylo-oligosaccharides via Maillard reaction: characterization, antioxidant capacity, and application for lycopene microencapsulation. LWT - Food Science and Technology, 118, 108837.

Krasaekoopt, W., Bhandari, B., Deeth, H.C. 2006. Survival of probiotics encapsulated in chitosan-coated alginate beads in yoghurt from UHT- and conventionally treated milk during storage. $L W T, 39,177-183$.

Lau, W.K., Van Chuyen, H., Vuong, Q.V. 2018. Physical Properties, Carotenoids and Antioxidant Capacity of Carrot (Daucus carota L.) Peel as Influenced by Different Drying Treatments. International Journal of Food Engineering, 14(3), 1-13.

Meybodi, N.M., Mortazavian, A.M., Arab, M., Nematollahi, A. 2020. Probiotic viability in yoghurt: A review of influential factors. International Dairy Journal, 109, 104793.

Mihalcea, L., Turturică, M., Barbu, V., Ioniță, E., Pătraşcu, L., Cotârleț, M., Dumitrascu, L., Aprodu, I., Râpeanu, G., Stănciuc, N. 2018. Transglutaminase mediated microencapsulation of sea buckthorn supercritical $\mathrm{CO} 2$ extract in whey protein isolate and valorization in highly value added food products. Food Chemistry, 262, 30-38.

Mihalcea, L., Turturică, M., Cucolea, E.I., Dănilă, G.M., Dumitrașcu, L., Coman, G., Constantin, O.E., Grigore-Gurgu, L., Stănciuc, N. 2021. $\mathrm{CO}_{2}$ Supercritical Fluid Extraction of Oleoresins from Sea Buckthorn Pomace: Evidence of Advanced Bioactive Profile and Selected Functionality. Antioxidants, 10, 1681.

Mihalcea, L., Turturica, M., Ghinea, I.O., Barbu, V., Ionita, E., Cotarlet, M., Stanciuc, N. 2017. Encapsulation of carotenoids from sea buckthorn extracted by CO2 supercritical fluids method within whey proteins isolates matrices. Innovative Food Science and Emerging Technologies, 42, 120-129.

Oancea, A.M., Hasan, M., Vasile, A.M., Barbu, V., Enachi, E., Bahrim, G., Rapeanu, G., Silvi, S., Stanciuc, N. 2018. Functional evaluation of microencapsulated anthocyanins from sour cherries skins extract in whey proteins isolate. LWT - Food Science and Technology, 95, 129-134.

Ozdal, T., Capanoglu, E., Altay, F. 2013. A review on protein-phenolic interactions and associated changes. Food Research International, 51, 954-970.

Pan, L.-H., Liu, F., Luo, S.-Z., Luo, J.-P. 2019. Pomegranate juice powder as sugar replacer enhanced quality and function of set yoghurts: Structure, rheological property, antioxidant activity and in vitro bioaccessibility. LWT-Food Science and Technology, 115, 108479.

Pinto, J., Spinola, V., Llorent-Martinez, E.J., Fernandez-de Cordova, M.L., Molina- Garcia, L., Castilho, P.C. 2017. Polyphenolic profile and antioxidant activities of Madeiran 
elderberry (Sambucus lanceolata) as affected by simulated in vitro digestion. Food Research International, 100, 404-410.

Purkiewicz, A., Ciborska, J., Tańska, M., Narwojsz, A., Starowicz, M., Przybyłowicz, K.E., Sawicki, T. 2020. The impact of the method extraction and different carrot variety on the carotenoid profile, total phenolic content and antioxidant properties of juices. Plants, $\mathbf{9}$, 1759.

Ravindran, R., Jaiswal, A.K. 2016. Exploitation of food industry waste for high-value products. Trends in Biotechnology, 34, 58-69.

Rodríguez-Huezo, M.E., Pedroza-Islas, R., Prado-Barragán, L.A., Beristain, C.I., VernonCarter, E.J. 2004. Microencapsulation by spray drying of multiple emulsions containing carotenoids. Journal of Food Science, 69, 351-359.

Sampaio, G.L.A., Pacheco, S., Ribeiro, A.P.O., Galdeano, M.C., Gomes, F.S., Tonon, R.V., 2019. Encapsulation of a lycopene-rich watermelon concentrate in alginate and pectin beads: characterization and stability. LWT - Food Science and Technology, 116, 108589.

Sandoval-Castilla, O., Lobato-Calleros, C., García-Galindo, H.S., Alvarez-Ramírez, J., Vernon-Carter E.J. 2010. Textural properties of alginate-pectin beads and survivability of entrapped $\mathrm{Lb}$. casei in simulated gastrointestinal conditions and in yoghurt. Food Research International, 43, 111-117.

Šeregelj, V., Pezo, L., Šovljanski, O., Lević, S., Nedović, V., Markov, S., Tomić, A., Čanadanović-Brunet, J., Vulić, J., Tumbas Šaponjac, V., Ćetković, G. 2021. New concept of fortified yogurt formulation with encapsulated carrot waste extract. LWT - Food Science and Technology, 138, 110732.

Skrede, G., Wrolstad, R.E., Durst, R.W. 2000. Changes in Anthocyanins and Polyphenolics During Juice Processing of Highbush Blueberries (Vaccinium corymbosum L.). Journal offood science, 65(2), 357-364.

Skryplonek, K., Henriques, M., Gomes, D., Viegas, J., Fonseca, C., Pereira, C., Dmytrów, I., Mituniewicz-Małek, A. 2019. Characteristics of lactose-free frozen yogurt with $\kappa$ carrageenan and corn starch as stabilizers. Journal of Dairy Science, 102(9), 7838-7848.

Stojadinovic, M., Radosavljevic, J., Ognjenovic, J., Vesic, J., Prodic, I., Stanic-Vucinic, D., Velickovic, T.C. 2013. Binding affinity between dietary polyphenols and b- lactoglobulin negatively correlates with the protein susceptibility to digestion and total antioxidant activity of complexes formed. Food Chemistry, 136, 1263-1271.

Sun, L.Q., Ding, X.P., Qi, J., Yu, H., He, S.a., Zhang, J., Ge, H.X., Yu, B.Y. 2012. Antioxidant anthocyanins screening through spectrum-effect relationships and DPPHHPLC-DAD analysis on nine cultivars of introduced rabbiteye blueberry in China. Food Chemistry, 132, 759-765.

Szczepańska, J., Skąpska, S., Lorenzo, J.M., Marszałek, K. 2021. The Influence of Static and Multi-Pulsed Pressure Processing on the Enzymatic and Physico-Chemical Quality, and Antioxidant Potential of Carrot Juice During Refrigerated Storage. Food and Bioprocess Technology, 14(1), 52-64.

Szczepańska, J., Skąpska, S., Połaska, M., Marszałek, K. 2022. High pressure homogenization with a cooling circulating system: The effect on physiochemical and rheological properties, enzymes, and carotenoid profile of carrot juice. Food Chemistry, 370, 131023.

Taksima, T., Limpawattana, M., Klaypradit, W. 2015. Astaxanthin encapsulated in beads using ultrasonic atomizer and application in yogurt as evaluated by consumer sensory profile. Lebensmittel-Wissenschaft und -Technologie- Food Science and Technology, 62, 431-437. 
Terpou, A., Gialleli, A.I., Bekatorou, A., Dimitrellou, D., Ganatsios, V., Barouni, E., Koutinas, A.A., Kanellaki M. 2017a. Sour milk production by wheat bran supported probiotic biocatalyst as starter culture. Food and Bioproducts Processing, 101, 184-192.

Terpou, A., Gialleli, A.I., Bosnea, L., Kanellaki, M., Koutinas, A.A., Castro. G.R. 2017b. Novel cheese production by incorporation of sea buckthorn berries (Hippophae rhamnoides L.) supported probiotic cells. LWT - Food Science and Technology, 79, 616624.

Terpou, A., Papadaki, A., Bosnea, L., Kanellaki, M., Kopsahelis, N. 2019. Novel frozen yogurt production fortified with sea buckthorn berries and probiotics. LWT - Food Science and Technology, 105, 242-249.

Ursache, F.M., Andronoiu, D.G., Ghinea, I.O., Barbu, V., Ioniță, E., Cotârleț, M., et al. 2018. Valorizations of carotenoids from sea buckthorn extract by microencapsulation and formulation of value-added food products. Journal of Food Engineering, 219, 16-24.

Ursache, F.M., Ghinea, I.O., Turturică, M., Aprodu, I., Râpeanu, G., Stănciuc, N. 2017. Phytochemicals content and antioxidant properties of sea buckthorn (Hippophae rhamnoides L.) as affected by heat treatment - Quantitative spectroscopic and kinetic approaches. Food Chemistry, 233, 442-449.

Vulić, J., Šeregelj, V., Kalŭsević, A., Lević, S., Nedović, V., Tumbas Šaponjac, V., et al. 2019. Bioavailability and bioactivity of encapsulated phenolics and carotenoids isolated from red pepper waste. Molecules, 24, 2837.

Zygmantaité, G., Kešsiené, M., Jasutiené, I., Šipailiené, A., Rimantas Venskutonis, P., Leskauskaité, D. 2021. Extract isolated from cranberry pomace as functional ingredient in yoghurt production: Technological properties and digestibility studies. LWT - Food Science and Technology, 148, 111751. 